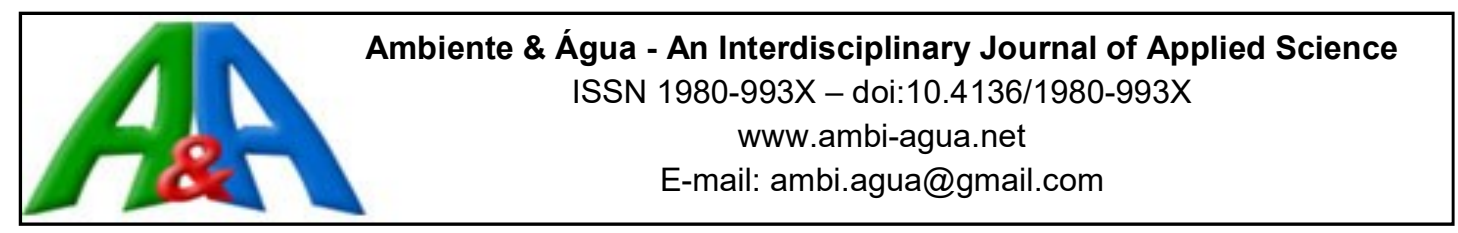

\title{
O direito humano de acesso à água potável: uma análise continental baseada nos Fóruns Mundiais da Água
}

\author{
doi:10.4136/ambi-agua.1861
}

Received: 11 Feb. 2016; Accepted: 11 Jul. 2016

\author{
Lorenzo Zorzi ; Luciana Turatti; Jane Márcia Mazzarino \\ Centro Universitário UNIVATES, Lajeado, RS, Brasil \\ Programa de Pós Graduação em Ambiente e Desenvolvimento (PPGAD) \\ *Autor correspondente: e-mail: lorenzo.zorzi1990@gmail.com, \\ lucianat@univates.br, janemazzarino@univates.br
}

\section{RESUMO}

Até finais da década de 80 , o desenvolvimento e os direitos humanos eram tratados como temas isolados, possuindo estratégias e objetivos distintos e divergentes. Passadas duas décadas, compreende-se que não há como dissociar os dois temas. Na atualidade, os direitos humanos são objeto de uma crescente promoção, especialmente com enfoque baseado no marco conceitual do desenvolvimento humano, o qual se baseia em normas internacionais e persegue o objetivo de fomentá-los e protegê-los. É neste contexto que se insere o direito ao acesso à água potável, o qual, após inúmeras tratativas, passou a ser compreendido como direito humano. O objetivo deste artigo é discutir a questão da água como direito humano, a partir da análise dos Fóruns Mundiais da Água que acontecem desde 1997 e envolve os setores público, privado, não governamental e científico. O método da pesquisa é qualitativo, baseado na análise textual qualitativa dos documentos destes eventos.

Palavras-chave: análise documental, direito humano à água, Fórum Mundial da Água.

\section{The human right of access to drinking water: a continental analysis based on World Water Forums}

\begin{abstract}
At the end of the 1980s, development and human rights were treated as separate issues, with distinct and divergent strategies and goals. After two decades, our understanding of the issue has evolved, and it has become clear that there is no way to separate the two issues. Currently, interest in human rights is increasing, and is focusing particularly on developing a consensus based upon international standards in order to promote and protect such rights. In this context, after numerous negotiations, the right to access potable water has come to be understood as a human right. This paper discusses the issue of water as a human right based upon the analysis of the World Water Forum which has existed since 1997 and involves the public, private and scientific sectors. The qualitative textual analysis was based upon documentation of these events.
\end{abstract}

Keywords: document analysis, human right to water, World Water Forum. 


\section{OS DIREITOS HUMANOS}

Os direitos humanos são objeto de uma crescente promoção, especialmente através do enfoque inspirado no marco conceitual do desenvolvimento humano, o qual se baseia em normas internacionais e persegue o objetivo de fomentá-los e protegê-los. Isto porque entende-se que as desigualdades, as práticas discriminatórias e a distribuição de poder injustas impedem o avanço do desenvolvimento. Pautado em tais premissas, discute-se a garantia de acesso à água potável, uma vez que esta se consagra como direito humano a partir das orientações contidas nas normativas internacionais e requer, portanto, a ação dos diversos Estados para sua concreção.

A Declaração Universal dos Direitos Humanos - "Universal Declaration of Human Rights" (UDRH) ${ }^{1}$ aprovada em 1948, após o fim da Segunda Guerra Mundial, prevê que o reconhecimento da dignidade inerente e dos direitos iguais e inalienáveis de todos os membros da família humana são fundamentos da liberdade, da justiça e da paz no mundo (UNESCO, 1948).

Conforme os ditames da Declaração de Viena a UDRH se constitui como modelo de normas morais e políticas a serem atingidas por todos os povos e por todas as Nações, sendo fonte de inspiração para as Nações Unidas no sentido de avançar em relação aos instrumentos de direitos humanos (UN, 1993).

A Alta Comissão dos Direitos Humanos da Organização das Nações Unidas (ONU) vem tentando trabalhar para reforçar certos direitos humanos, vez que estes se colocam como universais e internacionais e, para tanto, estabeleceu normativas a esse respeito. É neste interim que surge a Comissão dos Direitos Econômicos, Sociais e Culturais (CESCR), a qual em 1985, por meio da resolução $n^{\circ} 1985 / 17$, recebeu a incumbência de implantar o Pacto Internacional sobre os Direitos Econômicos, Sociais e Culturais (ICESCR) (UN, 2015). O ICESCR tem sido reforçado por outras resoluções, destacando-se o Comentário Geral $n^{\circ} 15$, o qual reconheceu o direito humano à água como um direito econômico, social e cultural e destaca os motivos pelos quais a água pode ser reivindicada como tal:

O direito humano à água habilita todas as pessoas à água suficiente, segura, aceitável, fisicamente acessível e disponível para uso pessoal e doméstico. Uma quantidade adequada de água segura é necessária para evitar a morte por desidratação, para reduzir o risco de doenças relacionadas com a água e para fornecer água suficiente para o consumo, cocção, higiene pessoal (UN, 2003).

De tais afirmações, resta o entendimento de que negar às pessoas o acesso à água potável é negar-lhes o direito à vida. Além disso, a água deve estar disponível e cumprir certos níveis de qualidade. Melhorar a disponibilidade de abastecimento de água é crucial para a saúde pública, uma vez que este é o terceiro maior fator de risco para a saúde, principalmente em nações que estão em desenvolvimento, onde ocorrem as maiores taxas de mortalidade (WHO e SIWI, 2002).

Dentre os eventos que visam promover a causa da água, destacam-se os Fóruns Mundiais da Água organizados pelo Conselho Mundial da Água - "World Water Council" - os quais acontecem a cada 3 anos e mobilizam a criatividade, a inovação e o "know how" em torno da água, servindo como um primeiro passo para a colaboração global e o enfrentamento dos desafios. Os Fóruns são uma plataforma única, através da qual a comunidade do setor de água

${ }^{1}$ A UDRH foi revolucionária, uma vez que foi a primeira declaração a introduzir a ideia de que todas as pessoas merecem ser reconhecidas no sentido de ter dignidade e direitos iguais e inalienáveis, sendo os direitos humanos universais e internacionais (UN, 2015). 
e os responsáveis políticos de todas as Nações trabalham juntos para encontrar soluções conjuntas. Acontecem desde 1997, sendo um intercâmbio de experiências entre os setores público, privado, não governamental e científico.

Considerando o exposto, o objetivo deste estudo é compreender como a questão da água, enquanto direito humano, vem sendo tratada em nível continental nos Fóruns Mundiais da Água ocorridos entre os anos de 1997 e 2012, a partir da análise textual qualitativa.

\section{METODOLOGIA}

De acordo com Moraes (1999), na análise textual qualitativa tem-se a fragmentação dos textos e a síntese, para posterior reintegração dos elementos semelhantes em categorias formando novos textos, os quais reúnem os aspectos essenciais do objeto de análise. Os documentos consultados nesta pesquisa foram extraídos dos Fóruns Mundiais da Água, sendo que a maioria das informações obtidas foi encontrada nos relatórios finais dos respectivos fóruns. Em pesquisa no site do "World Water Council", que promove os Fóruns Mundiais da Água, não se obteve o relatório final do $1^{\circ}$ e do $2^{\circ}$ Fórum realizados nos anos de 1997 e 2000 em Marrakech e The Hague, respectivamente, sendo as informações obtidas através da página dos fóruns junto ao respectivo website. Somente no $4^{\circ}$ Fórum, além do relatório final, foram disponibilizados relatórios por continente. No $3^{\circ}, 5^{\circ}$ e $6^{\circ}$ Fórum Mundial da Água as informações foram obtidas unicamente do respectivo relatório final.

As informações coletadas referem-se à preocupação com a identificação do tratamento concebido à água na condição de direito humano. Para tanto, buscou-se pela palavra chave em inglês "human right". Conforme a metodologia adotada para a presente pesquisa, não observaram-se ocorrências da palavra-chave "human right" na declaração referente ao continente africano e ao Oriente Médio no $4^{\circ}$ Fórum Mundial da Água. Com exceção do $1^{\circ} \mathrm{e}$ do $2^{\circ}$ Fórum, em todos os demais $\left(3^{\circ}, 5^{\circ}\right.$ e $\left.6^{\circ}\right)$ foram observadas ocorrências da palavra chave buscada.

\section{ANÁLISE DOS FÓRUNS MUNDIAIS DA ÁGUA}

Conforme já referenciado, o Fórum Mundial da Água é organizado pelo Conselho Mundial da Água - "World Water Council" (WWC) - desde 1997, e acontece a cada 3 anos com foco na criatividade, na inovação e no "know how" em torno da água, servindo como um primeiro passo para a colaboração global e superação dos desafios impostos para governança da água. O WWC é composto por cerca de 300 atores do setor público, privado e organizações da sociedade civil, sendo financiado pelos seus membros através de doações de organizações internacionais. Foi criado, em 1996, devido à crescente preocupação da comunidade internacional com as questões relacionadas à água (Portal ODM, 2015).

Os Fóruns são organizados conjuntamente pelo país anfitrião e pelo WWC, através do qual a comunidade do setor de água e os responsáveis políticos e representantes de todas as Nações trabalham para encontrar soluções conjuntas. Sua importância global se deve ao fato deste buscar dar reconhecimento à temática dos recursos hídricos. São organizados durante um período de dois anos, que antecedem ao evento, por meio de um processo preparatório. Cada Fórum é composto pelo Fórum Temático, onde acontecem as sessões, cada qual com um assunto específico, e pela Conferência Ministerial, que acontece entre ministros do governo e os participantes do Fórum, e tem o objetivo de garantir que os atores locais forneçam opiniões no que tange às políticas hídricas.

Os grupos de interesse nos Fóruns são as crianças e jovens, as mulheres, os povos indígenas, as organizações não governamentais e as autoridades locais. Este público foi selecionado para assegurar que todos os pontos de vista sejam lembrados durante os debates 
nos Fóruns. Cada grupo participante tem direito a sua própria declaração. Há de se referir ainda que os relatórios não especificam quais foram as ONGs participantes, ou ainda os demais grupos da sociedade. Quanto aos países participantes, não se encontrou a identificação dos mesmos no $1^{\circ}, 2^{\circ}, 5^{\circ}$ e $6^{\circ}$ Fórum Mundial da Água.

\section{1. $1^{\circ}$ Fórum Mundial da Água}

O $1^{\circ}$ Fórum Mundial da Água foi sediado em Marrakech, Marrocos, em 1997. Teve a participação de 63 países e um total de 500 participantes, sendo o tema principal do evento "Um olhar para a água, a vida e ao ambiente". A única informação obtida na página deste Fórum no site do "World Water Council" é que a Declaração de Marrakech incluiu o reconhecimento da água limpa e potável como necessidade humana básica.

Os principais temas abordados no $1^{\circ}$ Fórum Mundial da Água centraram-se no reconhecimento da necessidade humana básica, no sistema de gestão pública, na proteção dos ecossistemas e na igualdade de gêneros, bem como na cooperação entre o governo e a sociedade civil e na vazão eficiente da água. Devido à não disponibilização do relatório final para análise, não foi possível aprofundá-la assim como pretendido.

\section{2. $2^{\circ}$ Fórum Mundial da Água}

Foi sediado em "The Hague" na Holanda entre os dias 17 e 22 de março de 2000. O tema principal do evento foi "Da Visão à Ação", contabilizando 5.700 participantes advindos de 114 países.

A abordagem principal deste evento esteve focada nas mulheres, nos jovens e crianças, bem como nas Organizações não Governamentais (ONGs) e no "Corporate Europe Observatory" (CEO). As ações prioritárias tiveram como foco "design", energia, ética e economia, bem como algumas regiões específicas (Ásia, África e Mediterrâneo).

Como já mencionado, não foi encontrado o relatório final referente ao $2^{\circ}$ Fórum Mundial da Água, mas segundo a Declaração Ministerial disponível no site do "World Water Council", foi objetivado assegurar água potável para o século 21 .

\section{3. $3^{\circ}$ Fórum Mundial da Água}

O $3^{\circ}$ Fórum Mundial da Água foi sediado em Kyoto, Shiga e Osaka no Japão entre os dias 16 e 23 de Março de 2003 e contou com 24.000 participantes de 183 países. O tema principal deste evento foi "O Fórum como a diferença" e as principais ações resultantes deste Fórum foram o desenvolvimento de políticas, o gerenciamento de recursos hídricos, a mitigação de desastres naturais e a prevenção da poluição.

Ressalta-se que no continente africano, através do Conselho dos Ministros da África sobre a Água e da Força-Tarefa da Água, foram estabelecidas políticas de desenvolvimento com iniciativas para preparar uma agenda da água a partir da visão africana. Tal mecanismo seria um canal facilitador para capacitação e apoio aos investimentos realizados na África.

Neste $3^{\circ}$ Fórum Mundial da Água, foram estabelecidos alguns objetivos a serem atingidos a curto prazo como (WWC, 2003):

- Desenvolvimento de metas globais com base em realidades locais, e metas nacionais para melhorar o saneamento com abordagens centradas nas pessoas e com foco no acesso à água como direito humano;

- Desenvolvimento e fortalecimento de políticas e estruturas institucionais para melhorar o saneamento, o abastecimento de água potável e a adequada higiene, incluindo respeito e gerenciamento;

- Desenvolvimento de campanhas em nível nacional a fim de proporcionar ambientes saudáveis às crianças, envolvendo todos os setores da sociedade na consecução dos objetivos; 
- Integração de saneamento e controle da poluição na gestão de recursos hídricos.

Foi recomendado que os governos reconhecessem e consagrassem a água como um direito humano, por meio do qual as pessoas tivessem o direito de acessar água potável em quantidade suficiente para uso pessoal e doméstico.

Os assuntos prioritários foram o acesso à água e ao saneamento como um direito humano básico. Foi manifestado que todas as pessoas devem ter segurança hídrica e saneamento adequado para satisfazer as suas necessidades básicas, incluindo a água usada para fins de produção e subsistência. $\mathrm{O}$ acesso à água e ao saneamento foi compreendido como um componente chave de qualquer estratégia para amenizar a pobreza e permitir que as mulheres conquistem seu espaço na sociedade. Foi recomendado que todos os Estados-Nação reconhecessem a água e o saneamento como direito humano básico.

Além disso, considerou-se de extrema prioridade que os governos integrassem as questões relacionadas à água com os aspectos da saúde, silvicultura, agricultura, segurança alimentar local e proteção dos ecossistemas, tendo o empoderamento das mulheres, dos jovens, dos indígenas e das comunidades marginalizadas como foco principal. Ficou claro neste $3^{\circ}$ Fórum que a conexão entre os direitos humanos e as considerações ambientais é intrínseca e que a proteção ao meio ambiente permite a proteção dos seres humanos e suas necessidades fisiológicas, culturais e espirituais.

$\mathrm{Na}$ Declaração dos Jovens - "Youth World Water Forum Statement" - apresentada durante o $3^{\circ}$ Fórum Mundial da Água e que consta no relatório final do evento (WWC, 2003), é expresso o desejo de que todas as pessoas tenham o direito de acesso à água por meio da interação entre "stakeholders". Este direito deve ser interpretado de forma a permitir que qualquer indivíduo possa satisfazer as suas necessidades humanas básicas, incluindo o uso da água para subsistência.

Ademais, a declaração reiterou que os jovens deveriam ser consultados na tomada de decisões dos governos e expôs que a ética, a vontade, a confiança, a honestidade e a moral são fundamentais para garantir um desenvolvimento a longo prazo, centrado na sustentabilidade e nos direitos humanos.

O Conselho Mundial da Água aponta as parcerias entre os setores público e privado como "solução" para criar novas estruturas e métodos que garantam o direito da população ao acesso à água, de modo a manter o ritmo entre o desenvolvimento e o crescimento da população e fechar a lacuna existente na distribuição de água para população pobre. $\mathrm{O}$ acordo estabelecido foi de que o acesso à água é um direito humano, que os recursos hídricos são um bem comum, a ser controlado pelos governos em nome dos cidadãos, e que os governos têm a responsabilidade de fornecer água potável e saneamento para todos os cidadãos.

Na Declaração das Organizações não Governamentais - "NGO Statement" - também apresentada durante o $3^{\circ}$ Fórum, afirmou-se que a água é um bem público e seu acesso de forma segura é direito humano, sendo que as ONGs (não são mencionadas quais ONGs em específico) declaram sua oposição em relação ao paradigma de desenvolvimento exemplificado pela mercantilização da água. Como recomendações, os governos deveriam reafirmar o compromisso de que o acesso à água e ao saneamento se caracterizam como direito humano básico perante a Declaração de Kyoto, além de respeitar e proteger os direitos humanos em todas as decisões políticas sobre a água na gestão dos recursos hídricos.

Portanto, no $3^{\circ}$ Fórum Mundial da Água, finalmente, o direito humano à água foi oficialmente reconhecido pelo Conselho Econômico e Social da ONU, no entanto, este princípio não foi incorporado na Declaração Ministerial (elaborada pelos ministros que representam cada país participante no Fórum, a fim de estabelecer diretrizes e consensos alcançados durante a discussão nos Fóruns), porque não houve acordo entre os ministros participantes. Sendo assim, apesar da ONU reconhecer este direito, tal reconhecimento não gerou consequências jurídicas para os países. 
Embora não se tenha informações sobre a questão envolvendo o direito humano à água nos cinco continentes, de modo geral, a visão deste $3^{\circ}$ Fórum em Kyoto é que a Ásia e o Pacífico enfrentam o desafio de conciliar o crescimento populacional com a disponibilidade de água, enquanto a pobreza persiste na África em um ciclo de conflito, sofrimento e subdesenvolvimento. Em relação a América, é relatado que investimentos em projetos e reformas de infraestrutura de acesso à água falharam para estimular o crescimento econômico sustentável. No contexto do Oriente Médio, a diminuição da disponibilidade de água ameaça a vida da população, a proteção ao ambiente e o desenvolvimento do continente, enquanto os recursos hídricos na Europa sujeitam-se à pressão, devido ao aumento da densidade populacional e da atividade industrial e agrícola.

\section{4. $4^{\circ}$ Fórum Mundial da Água}

O $4^{\circ}$ Fórum Mundial da Água foi realizado na Cidade do México, México, entre 16 e 22 de março de 2006. Cerca de 20 mil pessoas de 168 países participaram a fim de discutir sobre o tema principal do evento - Ações locais para uma mudança global. Os assuntos prioritários do $4^{\circ}$ Fórum Mundial da Água envolveram o gerenciamento de riscos, água e saneamento, implementação de gestão integrada de recursos hídricos (IWRM) e água para fins de desenvolvimento (WWC, 2006).

Neste Fórum, foi aprovada uma declaração ministerial que reforça a necessidade de inclusão da água e do saneamento como prioridades nacionais de desenvolvimento sustentável. Frente a isso, a Bolívia propôs uma declaração complementar - Declaração Complementar no Âmbito do $4^{\circ}$ Fórum Mundial da Água - elaborada juntamente com Cuba, Venezuela e Uruguai, indicando que o acesso à água com qualidade, quantidade e equidade constitui um direito humano fundamental.

O Uruguai apoiou a iniciativa da Bolívia por já ter incorporado em sua Constituição a água na condição de recurso natural fundamental para os seres humanos, considerando o acesso à água potável e ao saneamento como direitos humanos básicos.

Ainda sobre a respectiva declaração, ficou estabelecido que os Estados, com a participação da comunidade, devem esforçar-se em todos os níveis de modo a garantir o acesso à água como direito humano fundamental dentro dos seus Países. Além disso, destaca-se que a Bolívia, Cuba, Uruguai e Venezuela reafirmaram o direito soberano de cada país de adotar regulamentos sobre a água, seus usos e serviços, além de propor que todos os Estados promovam o Fórum Mundial da Água a partir de uma perspectiva multilateral e internacional, com base nos princípios de participação e inclusão. No que se refere à Bolívia, o artigo 20 da sua "Constituição Política do Estado Plurinacional" considera que o acesso à água e ao saneamento constituem direitos humanos, não são objeto de concessão nem de privatização e estão sujeitos a regimes de licenças e registros (Bolívia, 2008).

É destacado que o Uruguai se tornou o primeiro país da América a incluir o acesso à água potável e ao saneamento como direito humano fundamental em sua Constituição, sendo que desde 2002 vem conseguindo consolidar uma visão alternativa da água na sociedade, a qual baseia-se no fato de que a água é um direito humano fundamental e, portanto, uma estratégia de gestão participativa.

Esta iniciativa deu origem à Comissão Nacional em Defesa da Água e da Vida e, mais tarde, em 2004, após uma reforma constitucional amparada por um plebiscito, foi proibida no País a privatização da água. Em 2009 foi criada a Lei de Política Nacional de Águas, momento no qual foram canceladas todas as concessões às empresas privadas relacionadas com a água potável. Em 2009, a transferência do último fornecimento de água potável foi concluída por uma empresa privada, envolvendo cem por cento de serviços prestados por parte do Estado (Moreira, 2009). Este plebiscito não tem precedentes na história do mundo. Sua inclusão na Carta Magna em um país no caminho da democracia direta elevou a proteção 
da água a condição de direito, opondo-se a sua privatização e confirmando-a como direito de todos.

Costa Rica e Guatemala também foram mencionados por terem adotado estratégias de gerenciamento integrado de recursos hídricos como um meio para atingir os objetivos nacionais. Neste contexto, é relatado que o crescimento econômico do Chile motivou a criação de políticas sobre a água para alcançar as metas nacionais de desenvolvimento (Peña, 2005). Da mesma forma, no México, a água é vista como uma questão de segurança nacional. Lá, a gestão da água está diretamente conectada ao desenvolvimento nacional do país ${ }^{2}$.

É relatado, no $4^{\circ}$ Fórum Mundial da Água, que o continente americano está somando esforços a fim de tornar a água um bem econômico, o que se contraporia a toda evolução alcançada no sentido de classificá-la como direito humano. Tal fato gerou conflitos entre grupos da sociedade civil (não especificados no relatório) que alegaram que apenas os grupos populacionais mais ricos seriam beneficiados, enquanto os pobres estariam excluídos do sistema. Percebe-se, entretanto, que a partir disto, os debates evoluíram em duas linhas no Fórum: entre aqueles que consideravam a água como um bem econômico e aqueles que a interpretavam como um direito humano. Mora (2004), por exemplo, defende a ideia de que o valor econômico da água cria condições que tornam possível assegurar o direito humano à água potável.

Estas desigualdades caracterizam-se como grandes desafios que devem ser enfrentados a partir de uma abordagem integradora, que inclui estratégias econômicas de crescimento dentro dos limites sustentáveis. O continente americano (norte e sul) vem relacionando a água como direito humano fundamental, inserindo a problemática como prioridade no âmbito das políticas públicas. A equidade no uso e distribuição da água e o acesso ao abastecimento de água para comunidades rurais são pontos fortes a serem destacados neste continente.

Foi exposta no $4^{\circ}$ Fórum Mundial da Água a importância de se definir objetivos de desenvolvimento nacional com a devida consideração das prioridades econômicas, sociais e ambientais, bem como definir o modelo econômico dos países com base nas características culturais de cada um, concomitantemente à realidade da sociedade e do contexto político.

Destaca-se que o princípio da água como direito humano foi enfatizado e reiterado por organizações da sociedade civil (não citadas no relatório), as quais estabeleceram seis princípios sobre a gestão dos recursos hídricos:

- A água é considerada como um direito humano fundamental e patrimônio natural e cultural das nações, sendo que deve ser garantido o acesso à água com qualidade e quantidade para todas as pessoas e sociedade, em especial para as comunidades pobres e para os setores mais vulneráveis;

- A água deve ser prioridade nas políticas públicas;

- A sociedade civil deve participar na tomada de decisões através de meios adequados e em níveis adequados de planejamento, gestão e regulação dos recursos hídricos;

- A gestão, utilização e distribuição da água deve ser feita de acordo com regras de justiça, equidade e sustentabilidade;

- Deve ser assegurado às comunidades rurais, o abastecimento de água a partir de normativas que garantam seu uso;

- Deve se realizar a gestão integrada da conservação das bacias hidrográficas, incluindo as transfronteiriças.

\footnotetext{
${ }^{2}$ No ano de 2009 a constituição do Equador também afirmou que o direito de acesso à água potável é um direito humano fundamental e irrenunciável. Tal direito foi declarado como patrimônio nacional estratégico de uso público, inalienável, imprescritível e essencial à vida (Equador, 2009).
} 
As questões que envolvem a água como direito humano ou como valor econômico podem fundir-se em um mesmo ponto de vista compatível e benéfico, sendo que o maior desafio neste caso refere-se ao desenvolvimento de mecanismos adequados para atingir os objetivos sociais e ambientais em nível nacional e em regiões estratégicas.

Como já mencionado, ministros de 148 delegações reconheceram a importância da relação entre a água para a saúde humana e o desenvolvimento social das comunidades, considerando que as especificidades locais devem ser levadas em conta na promoção de ações. Alguns ministros, embora não citado de quais países, levaram a pauta de que o acesso à água deve ser reconhecido como direito humano, devendo ser dispendidos, portanto, maiores recursos financeiros para garantir o acesso pela população carente. Tal proposta demonstra o intuito de iniciar-se um processo de ressignificação da água como um recurso natural que deve ser explorado de maneira sustentável e que proteja o ecossistema.

No contexto americano, a superação dos desafios que envolvem a água exige a definição de mecanismos adequados que permitam resolver as desigualdades existentes e garantir o crescimento econômico sustentável em toda a região. No que tange a América do Norte, as questões prioritárias relacionaram-se à qualidade da água e sua eficiência, enquanto os financiamentos em infraestrutura para apoiar o desenvolvimento econômico e social foram uma preocupação da América Latina e do Caribe.

De acordo com o relatório final deste Fórum, o continente europeu era promotor de ações fundamentadas na solidariedade, na igualdade e na justiça, sempre considerando a água como um direito humano. Além disso, os usuários de água afetados deveriam envolver-se nos processos de planejamento e na determinação dos custos relacionados ao fornecimento de água, os quais deveriam ser repartidos igualmente entre ricos e pobres. Considerou-se ainda a necessidade de criar mecanismos de solidariedade envolvendo todos os atores sociais, como governos, autoridades locais, grupos da sociedade civil, empresas privadas e instituições multilaterais. Embora os governos nacionais e locais devessem responsabilizar-se pelo desenvolvimento de sistemas de água e de saneamento, ações de solidariedade internacionais apoiariam 1,6 bilhões de pessoas em todo o mundo. Nas projeções realizadas, a aplicação do princípio de solidariedade permitiria que o custo da água não se transformasse em uma barreira para o abastecimento de água potável.

Relata-se ainda neste Fórum que na Europa os mecanismos de solidariedade contavam com forte compromisso e responsabilidade local dos organismos que fazem a gestão dos serviços de água e de saneamento, e isto faz com que estes aproximem-se dos usuários, identificando as melhores tecnologias em nível local, bem como a capacidade de pagamento dos serviços por parte da população.

$\mathrm{Na}$ declaração sobre o continente asiático, resultante do $4^{\circ}$ Fórum, constata-se que o conceito de segurança hídrica foi o tema chave para este continente, assegurando que o acesso à água como direito humano possibilita que todas as pessoas tenham alimentação segura e aceitável para fins pessoais e domésticos, conforme o disposto no Comentário Geral $\mathrm{n}^{\mathrm{o}} 15^{3}$ do Comitê dos Direitos Econômicos, Sociais e Culturais da Organização das Nações Unidas (UN, 2003).

A perspectiva, segundo este Fórum, é de que a gestão de recursos hídricos neste continente contemple um sistema dinâmico e, desta forma, não é possível pensar em segurança da água para a população sem que se tenha a garantia de que as bacias hidrográficas sejam bem administradas. Neste contexto, foi sugerido que as legislações sobre a gestão dos recursos hídricos sejam completas e que este planejamento seja adotado como base para o desenvolvimento em nível nacional, provincial, distrital e também na bacia, havendo uma gestão da demanda de água. Além disso, reconheceu-se que o direito de uso da

\footnotetext{
${ }^{3} \mathrm{O}$ Comentário Geral no 15 afirma que os estados são obrigados a garantir que todos tenham acesso à água suficiente, segura, aceitável, fisicamente acessível e disponível para uso pessoal e doméstico. 
água e a repartição equitativa carecem de mais estudos e do aprimoramento da capacidade de desenvolvimento institucional.

Os países da Ásia encontram-se em estágios distintos de desenvolvimento e assim, possuem níveis desiguais no que se refere à gestão das águas, pois isso depende essencialmente das prioridades de desenvolvimento e administração. Todos os países deste continente enfrentam fenômenos como períodos de cheias e secas, o que intensifica a necessidade de gerir de forma integrada e holística os recursos hídricos.

Quanto ao Oriente Médio, observa-se que não houve, no $4^{\circ}$ Fórum Mundial da Água, um manifesto sobre os direitos humanos, embora Israel tenha reconhecido a importância das novas tecnologias para remoção do sal da água do mar, além da reutilização de águas residuais, como forma de promover a gestão sustentável das zonas áridas e semi-áridas. Além disso, é evidente que os direitos relacionados à água neste continente não são claros e, muitas vezes, até são ausentes, impulsionando o uso irracional deste recurso por parte da comunidade, em especial pelo setor da agricultura.

Neste Fórum também foram defendidas ações referentes aos jovens, às Organizações Não Governamentais (ONG), às crianças, às mulheres e aos índios. As principais preocupações expressas pelas ONGs foram:

- A água, em todas as suas formas, é um bem comum e o acesso a esse bem é direito humano;

- A gestão dos recursos hídricos deve permanecer no setor público, com a participação social e comunitária, sem fins lucrativos;

- Os ecossistemas devem ser geridos de forma sustentável e o ciclo da água preservado por meio de manejo da terra e da conservação do meio ambiente;

- As fontes seguras de abastecimento de água devem ser fornecidas e protegidas por leis adaptadas às comunidades rurais e indígenas;

- As perspectivas de gênero devem ser integradas aos assuntos relacionados à água.

Quanto à declaração resultante do $4^{\circ}$ Fórum Mundial da Juventude que ocorreu paralelamente ao $4^{\circ}$ Fórum Mundial da Água, foi destacado o papel da água como um direito humano universal e inaliável, o qual deve ser escrito de acordo com as Constituições de cada país. De acordo com o relatado, os jovens podem contribuir na solução dos problemas hídricos, já que serão a próxima geração de gestores destes recursos.

Concomitantemente a estes eventos, ocorreu também o $2^{\circ}$ Fórum Mundial da Água para as crianças, através do qual foram elencadas algumas ações, como: o cumprimento do direito humano à segurança e o abastecimento de água potável e saneamento básico sustentável por meio de infraestrutura em escolas e comunidades, considerando as necessidades das crianças com deficiência. A água, vista como um direito humano universal e inalienável, deve ser incorporada na Constituição de cada país, devendo estar potável e prontamente disponível a partir de uma fonte segura e suficiente para a população.

No que tange à Declaração dos Povos Indígenas denominada "Tlatokan Atlahuak" foi reconhecida a relação deste povo com a "Mãe Terra" e a responsabilidade para com as gerações futuras, através da solidariedade e da proteção e defesa à água. Foi declarado que os povos indígenas rejeitam o modelo neoliberal que vê a água como mercadoria e não como um bem público e direito humano fundamental. Além disso, reafirmaram a sua autonomia no uso e aproveitamento dos recursos naturais, exigindo o reconhecimento dos seus costumes, leis e tradições.

Na Declaração das Mulheres, apresentada durante o Fórum, foram discutidas questões relacionadas ao direito humano à água, o qual muitas vezes tem sido negado as mulheres, o 
que conduz a sua exclusão em tomadas de decisões, a deterioração da saúde humana e "feminização" da pobreza.

\section{5. $5^{\circ}$ Fórum Mundial da Água}

Este Fórum ocorreu em Istambul, na Turquia entre os dias 16 e 22 de março do ano de 2009, teve como tema principal "Superando divisões de água" e contou com a participação de 192 países, totalizando 33.000 participantes (WWC, 2009).

Dentre as principais realizações destaca-se o comprometimento firmado entre 250 autoridades locais de 43 países para adotar melhorias nos planos de serviço de água locais. Através da Declaração de Istambul, os Chefes de Estado aprovaram a adoção de iniciativas que visavam ações eficazes no âmbito da água.

Os temas prioritários discutidos no $5^{\circ}$ Fórum Mundial da Água foram as mudanças climáticas, governança e finanças, gerenciamento de riscos, educação e desenvolvimento humano.

Já em relação aos direitos humanos, constata-se que este tema não foi efetivamente abordado neste Fórum, apesar da ênfase dada pelo vice-ministro da França, Chantal Jouanno no sentido de que o acesso à água e ao saneamento deve ser reconhecido como um direito humano e, assim, constar na Declaração Ministerial. Orellana Rene, ministra da Bolívia, afirmou que a questão do direito à água não está suficientemente representada na referida Declaração. No contexto espanhol, a ministra Elena Espinosa Mangana destacou que o acesso à água a baixo custo deve ser reconhecido como um direito humano, o que é essencial para questões relacionadas à segurança alimentar e energética. Bruno Oberle, vice-ministro da Suíça, considerou o acesso à água potável e ao saneamento como um direito humano básico, e afirma que a gestão sustentável dos recursos hídricos deve ser um dos pré-requisitos para alcançar as metas de desenvolvimento.

Durante o Fórum, algumas atividades tiveram como objetivo principal compartilhar experiências referentes ao uso do "Right to Water and Sanitation" (RTWS) como uma ferramenta que permite que as comunidades reivindiquem seus direitos. Esta discussão centrou-se nos desafios identificados e nos passos necessários para melhorar a capacidade das comunidades em utilizar o RTWS, a fim de que possam responsabilizar os governos e demais atores sociais a partir de uma perspectiva legal. Embora a Declaração Ministerial tenha reconhecido, em eventos anteriores, a água e o saneamento como direito humano, verificou-se que tal informação não consta na Declaração, aparecendo somente como uma necessidade humana básica.

No encerramento da Conferência Ministerial, um grupo representando as mulheres, enfatizou que a Declaração Ministerial preparada neste $5^{\circ}$ Fórum voltava no tempo, uma vez que esquecera os compromissos assumidos pelos governos nas outras edições: garantir o direito à água e ao saneamento. Reforçaram que o artigo 46 da Convenção sobre Eliminação de Todas as Formas de Discriminação Contra as Mulheres - "Convention on the Elimination of all forms of Discrimination Against Women" (CEDAW) - garante o direito à água para as mulheres rurais e destacaram, também, o atraso dos ministros referente a este assunto, pois ao invés de avançar na implementação de ações que asseguram o direito humano, em particular para a população carente, mulheres e crianças, ainda debatem se o direito à água e ao saneamento é ou não um direito humano.

$\mathrm{Na}$ Declaração dos Jovens foi solicitado que os governos os envolvam nas tomadas de decisões sobre a temática água, bem como na formulação de políticas e na gestão dos recursos hídricos. Declararam também que estes continuariam a insistir em um futuro que forneça o acesso à água potável para todos, aliado ao saneamento, considerando ambos como direitos humanos. Além disso, o tema sobre educação foi abordado, levando à compreensão de que é a única maneira para se chegar a formas sustentáveis de vida. Os jovens devem ser capacitados 
para ajudar a minimizar os impactos decorrentes da falta de água, afirma o documento.

A juventude, portanto, reconhece que o acesso à água potável e à igualdade de distribuição são necessidades de caráter vital e, por este motivo, devem ser consideradas como direito humano. Apelam, desta forma, para que a legislação de cada país defina a água como direito humano básico dentro de suas constituições e que este assunto seja discutido em nível internacional.

Em termos de governança e gestão, foi relatado que o direito humano à água não é apenas um direito de natureza individual,

e sim uma responsabilidade partilhada. Destaca-se que apesar da dificuldade de alguns países em concordar com o princípio da inclusão do direito à água na Declaração Ministerial, 32 países o incluíram em suas Constituições Nacionais (não foram especificados quais países).

\section{6. $6^{\circ}$ Fórum Mundial da Água}

O $6^{\circ}$ Fórum Mundial da Água teve como tema central "Tempo de Soluções" e ocorreu em Marseille, na França, entre 12 e 17 de março de 2012, com a participação de 173 países, contabilizando aproximadamente 34.000 participantes. Centrou-se em quatro ações prioritárias, sendo estas relacionadas ao desenvolvimento econômico, bem-estar, condições para o sucesso e manutenção da água no Planeta (WWC, 2012).

A maior conquista resultante deste Fórum foi o fato da Declaração Ministerial ter sido adaptada, promovendo a implementação do direito humano à água e ao saneamento de modo a garantir o bem-estar e a saúde humana.

Um dos principais assuntos abordados foi o desenvolvimento do continente africano com vistas a tornar a água um fator contribuinte para este processo a partir da segurança em face às mudanças climáticas, otimização da energia, produção de alimentos ou disponibilidade de água para uso doméstico e outros usos que contribuam em termos de cooperação e paz mundial. Foi elaborada uma declaração na qual consta o compromisso dos Estados em fazer com que a água e o saneamento sejam prioridades nas estratégias nacionais.

Também ficou acertado que os países que ratificaram o acordo irão garantir que a água seja um assunto de visibilidade na tratativa das negociações climáticas. Discutiu-se a inserção do direito humano à água e ao saneamento pela ONU, além da necessidade de integrar este princípio nas Constituições nacionais. Solicitou-se também que os governos mobilizem-se para fortalecer o Banco Africano de Desenvolvimento e Facilidade de Acesso à Água. Na oportunidade, a França contribuiu com 40 milhões de euros.

$\mathrm{O}$ bem-estar, visto como assunto estratégico neste $6^{\circ}$ Fórum foi discutido como prioridade, haja visto sua estreita relação com os direitos humanos. Neste sentido, a Assembleia Geral da ONU reconheceu o acesso à água e ao saneamento como tal.

Dentre as soluções desenvolvidas por diferentes regiões para enfrentar as suas necessidades hídricas e desafios dinâmicos, três eixos de ação destacaram-se como prioridade no $6^{\circ}$ Fórum Mundial da Água: desenvolvimento de programas em nível nacional, soluções técnicas e de gestão e de financiamento adaptado em nível local (áreas urbanas e rurais), além do monitoramento e da adoção de indicadores para avaliar a prestação de serviços. Estes eixos fundamentam-se na ideia principal de garantir o acesso à água para todos de forma a combater as disparidades remanescentes.

Foram reconhecidas várias políticas nacionais que abordam a dimensão do direito humano à água (México, Paquistão, África do Sul e Ucrânia), no entanto foi reforçado que todos os critérios devem ser atingidos por meio de políticas estratégicas que estabeleçam os prazos específicos para cada país, priorizando ações para cada contexto. Para tanto, as iniciativas nacionais devem ser flexíveis em relação à padrões de desenvolvimento e 
alterações demográficas, levando em conta a sustentabilidade dos serviços prestados e a garantia de continuidade dos mesmos.

Quanto ao monitoramento de abastecimento de água potável, destaca-se que a adoção dos Objetivos de Desenvolvimento do Milênio (ODM) com metas específicas e estabelecimento de indicadores contribuíram para o progresso global e isto comprova a necessidade de se ter monitoramento em nível local e global.

O Fundo das Nações Unidas para a Infância (UNICEF) juntamente com a "World Health Organization" (WHO) iniciaram a preparação das próximas metas globais, de indicadoreschave e de métodos de coleta de dados a fim de estabelecer critérios de abastecimento de água potável para todos os fins considerados como direito humano.

Outra prioridade resultante do Fórum sediado na França foi a melhoria do acesso aos serviços integrados de saneamento, a qual foi abordada em três vertentes:

- O direito ao saneamento básico com equidade e acessibilidade, incluindo atenção as necessidades específicas das mulheres e pessoas com deficiência;

- A abordagem integrada da prestação de serviços de saneamento, de modo a amenizar os impactos sociais e ambientais das águas residuais, com vistas à proteção dos ecossistemas;

- O planejamento e desenvolvimento de estratégias nacionais e locais com o objetivo de propor investimentos.

Tal assunto é coerente e faz referência a Resolução de 2011 da Assembleia da "World Health Organization" - WHO- 64/24 (WHO, 2011), uma vez que relaciona todas as questões que envolvem a água: saneamento, higiene, saúde e impactos positivos à sociedade como a redução de doenças transmitidas pela água contaminada. Para tanto, os governos nacionais, regionais e locais, bem como os órgãos reguladores têm o papel fundamental de acelerar a implementação de soluções em saneamento (coleta, tratamento e, quando possível, reutilização).

Aborda-se neste contexto, que a capacitação é um ponto importante a ser considerado quando se deseja implantar políticas e efetivá-las, e que os Estados têm a obrigação de respeitar, proteger e realizar o direito humano por meio de abordagens amplas e holísticas, que combinem estratégia, legislação, economia, governança, bem como elementos técnicos, sociais e operacionais.

Outro tema presente foi o da integridade e transparência no combate a corrupção na prestação de serviços de água e de saneamento e no que tange aos direitos humanos. Daí a importância do envolvimento de profissionais da mídia para aumentar a conscientização sobre os danos decorrentes de ações de corrupção neste setor, bem como incentivos aos princípios que integram o direito humano à água e ao saneamento, e ainda, a utilização de ferramentas de avaliação da governança (equidade, eficiência, sustentabilidade).

$\mathrm{O}$ direito humano à água e ao saneamento foi abordado em perspectivas continentais neste Fórum. Em relação às Américas foi enfatizado que a garantia do acesso universal à água e ao saneamento é um desafio na América Latina e no Caribe, pois embora a adoção da Declaração sobre os Direitos Humanos à Água e ao Saneamento pela ONU represente um considerável progresso, a implantação, de fato, destes direitos ainda é desafiadora. No entanto, é destacado novamente que México, Nicarágua, Uruguai, Bolívia, Equador, Paraguai e Costa Rica reconhecem este direito explicitamente em suas Constituições ou normas, enquanto muitos países ainda precisam transpor este direito aos seus sistemas jurídicos e definir planos de ações que traduzam a universalização da água potável e do saneamento de maneira adequada e financeiramente acessível.

A fim de promover a universalização da água e do saneamento na América Latina algumas propostas foram definidas no $6^{\circ}$ Fórum Mundial da Água, como: 
- Desenvolvimento de programas sociais que impliquem no Direito Humano à Água e ao Saneamento;

- Adaptação dos quadros jurídicos nacionais, a fim de reconhecer o Direito Humano à Água e ao Saneamento;

- Aceitação da reutilização de água com planos de comunicação articulados que garantam a aceitação do público em geral;

- Compreensão e gerenciamento da água de maneira economicamente, ambientalmente e socialmente responsável;

- Promoção do acesso à água potável e ao saneamento e adaptação conforme a realidade de cada comunidade;

- Criação da Comissão de Água no "Parlatino" (Latin America Parlamento);

- Criação de uma plataforma digital e programas de treinamento sobre água para jornalistas latino-americanos e organização de fóruns para os mesmos;

- Elaboração de manual orientando decisões políticas sobre a água.

Para dar consecução a tais propósitos, foram estabelecidos alguns compromissos como o do Banco Interamericano de Desenvolvimento (BID), no sentido de empenhar-se para continuar o processo de financiamento na América e promover o diálogo para a concepção e implementação de políticas públicas sobre o Direito Humano à Água e ao Saneamento. Além disso, o vencedor do prêmio "Ações de Água" deve relatar o progresso de suas atividades no $7^{\circ}$ Fórum Mundial da Água.

Quanto à Ásia, o principal assunto abordado refere-se a segurança d'água em zonas urbanas. Este continente almeja alcançar o acesso universal à água potável e ao saneamento até 2025. A base desta estratégia se dá por meio de um planejamento urbano sustentável e de design, de modo a dimensionar o crescimento da população e as redes básicas de água e de saneamento. Destacou-se que $72 \%$ da população asiática não têm acesso ao saneamento e que esta meta foi identificada considerando o marco da Resolução da Assembleia Geral da ONU de 2010, por meio do qual foi declarado o direito à água potável e limpa como um direito humano.

Foi discutida a importância da União Europeia (EU) adotar abordagens baseadas nos direitos humanos ao cooperar coletivamente com países não pertencentes a UE. Novas parcerias foram estabelecidas com algumas regiões do Caribe e da Ásia, além de já estarem trabalhando em conjunto com regiões da África, América Latina e Mediterrâneo. Sugeriu-se que, para estreitar cooperações e fortalecê-las, deve ser incluída a terceira reconstituição da "ACP-EU Water Facility" ${ }^{4}$ no âmbito do $11^{\circ}$ Fundo Europeu de Desenvolvimento, afim de facilitar ações nos países onde a água não é priorizada em programas nacionais; e ofertar empréstimos que gerem oportunidades, tais como a cooperação com o Fundo de Desenvolvimento Africano.

No que se refere às ONGs foram estabelecidas 9 palavras chaves, as quais foram desenvolvidas e apresentadas por vários colaboradores durante as sessões dedicadas ao tema "Soluções da Sociedade Civil", que tinha como foco a governança baseada nos direitos humanos: governança, água e segurança alimentar, saneamento, higiene e saúde, mudanças

${ }^{4}$ ACP-EU "Water Facility" é uma agência que foi instituída em 2004, com o objetivo de fornecer água e saneamento básico para a comunidade carente e melhorar a gestão da água no Caribe Africano e do Pacífico (ACP). Objetivos: ajudar a alcançar os Objetivos de Desenvolvimento do Milênio (ODM) e contribuir para melhorar a gestão da água e a gestão dos recursos hídricos para o desenvolvimento sustentável e a manutenção da infraestrutura de água (European Commission, 2015). 
climáticas, o direito humano à água e ao saneamento, desenvolvimento de capacidades, paz e cooperação transfronteiriça e finanças.

Durante o $6^{\circ}$ Fórum Mundial da Água aconteceram várias sessões, cada uma destinada a um assunto específico e dentre elas, destaca-se a sessão intitulada "Fazendo o Direito à Água uma Realidade para Todos" - "Making the Right to Water a reality for all" - o qual lembrou que o direito à água não é caridade, mas uma obrigação legal para todos os Estados, que devem comprometer-se e consagrá-la no seu sistema jurídico, bem como desenvolver políticas adequadas, ferramentas e mecanismos para torná-lo uma realidade para todos. Discutiram-se várias boas práticas como princípios dos direitos humanos à água e ao saneamento: acessibilidade, disponibilidade, não discriminação, responsabilidade, participação e acesso à informação.

$\mathrm{Na}$ oportunidade, foram examinados os compromissos políticos apresentados pela Espanha e pela Alemanha através da "Declaração do Grupo Azul" - "Blue Group Declaration". Três prioridades para o futuro foram destacadas nesta declaração, sendo elas (Blue Group Declaration, 2012):

- Acessibilidade: os atores devem desenvolver tecnologias que façam com que os serviços e preços sejam acessíveis para todos, podendo a implementação de subsídios intersetoriais ser uma opção;

- Inclusão e equidade: deve ser dada prioridade às pessoas mais vulneráveis, especialmente em áreas urbanas;

- Indicadores após 2015: novos indicadores do direito humano à água e ao saneamento devem ser utilizados como critérios para elaboração dos Objetivos do Milênio e da Agenda pós-2015.

\section{DISCUSSÃO DOS RESULTADOS}

Ressalta-se que não há uma compreensão universal sobre o tema direitos humanos, pois como pôde ser observado na esfera continental, a Europa encontra-se em um estágio avançado no que tange a este assunto, uma vez que promove ações fundamentadas na solidariedade e considera a água como um direito humano fundamental, sendo um continente visto como referência, embora muitos dos seus países não tenham reconhecido o acesso à água como direito humano nos textos constitucionais.

Já quanto ao Continente Americano, a América do Norte encontra-se em um estágio de desenvolvimento superior a América do Sul, o que faz com que esta região ainda tenha que realizar grandes investimentos em infraestrutura para apoiar o desenvolvimento econômico e social e levar água para todos os indivíduos, mesmo estes vivendo em regiões onde existe muita desigualdade social. Em contraponto, a América do Norte tem a qualidade da água e sua eficiência como assuntos prioritários. No entanto, percebe-se que, embora a América do Sul não tenha o padrão de desenvolvimento europeu, ele tem o direito humano à água reconhecido na Constituição de muitos dos seus países (México, Nicarágua, Uruguai, Bolívia, Equador, Paraguai e Costa Rica). Isto pode estar associado a fatores culturais, uma vez que na América do Sul há forte descendência indígena, que tem como marca a relação harmônica com a natureza.

Quanto ao continente asiático, verificou-se que existe desigualdade entre os países, principalmente ao que se refere à forma de gerenciar os recursos hídricos e à sobreposição de competências e de funções das agências reguladoras. Tal gestão se faz necessária, pois os países são afetados por fenômenos climáticos, como períodos de cheias e de estiagens, que exigem uma maneira integrada de gestão. Associa-se a este fato o crescimento da população e a consequente elevação na demanda pelo consumo de água. 
O Oriente Médio vem sofrendo com escassez de água, tendo que usar tecnologias para dessalinizá-la, além do fato de não haver uma gestão da água eficaz, o que impulsiona o uso irracional deste recurso, principalmente para fins agropastoris. Além disso, este continente vem sofrendo conflitos de origens distintas, como civis e religiosas.

Sendo o continente africano aquele que mais sofre com a escassez de água, é impossível pensar que o direito humano à água esteja garantido, pois a pobreza tem limitado o desenvolvimento da África, gerando conflitos, sofrimento e subdesenvolvimento. Além disso, os conflitos que acontecem neste continente acabam desestimulando investimentos e o setor de água, em especial, caracteriza-se como um dos principais desafios dos países africanos.

A análise textual dos temas dos seis Fóruns Mundiais da Água aponta que, nos primeiros dois, assumiu-se uma proposta de discussão mais generalista e menos problematizadora: necessidade humana básica, sistema de gestão pública, proteção de ecossistemas, igualdade de gêneros, cooperação entre governos e sociedade civil ( $1^{\circ}$ Fórum), design, energia, ética, economia ( $2^{\circ}$ Fórum). Estas diversidades temáticas demonstram uma aproximação ao tema. Já no terceiro Fórum, surgem questões como desastres naturais e poluição, assim como a necessidade de desenvolvimento de políticas e a preocupação com o gerenciamento, dando um tom mais político e ecológico para a proposta de debate.

Este enfoque vai se repetir nos Fóruns subsequentes quando se selecionam como temas: gerenciamento de riscos, gestão integrada, água para o desenvolvimento e água e saneamento ( $4^{\circ}$ Fórum), mudanças climáticas, governança, finanças, gerenciamento de riscos, educação e desenvolvimento humano ( $5^{\circ}$ Fórum), desenvolvimento econômico, bem-estar, condições para o sucesso e manutenção da água no planeta ( $6^{\circ}$ Fórum).

Percebe-se a reincidência do termo desenvolvimento a partir do terceiro Fórum, mesmo que associado a diferentes perspectivas: de políticas, água como condição para o desenvolvimento, desenvolvimento humano e econômico, o que demonstra que o desenvolvimento não é interpretado a partir de uma noção integral, complexa e holística, e sim entendido como algo fragmentado, como se um tipo de desenvolvimento fosse possível sem os outros.

A governança surge perifericamente com o tema cooperação entre governos e sociedade civil ( $1^{\circ}$ Fórum) e governança ( $5^{\circ}$ Fórum). Outros temas periféricos são a questão dos ecossistemas, de gênero, design, energia e ética ( $1^{\circ}$ e $2^{\circ}$ Fórum).

Entre as temáticas mais recorrentes estão a gestão e o gerenciamento dos recursos hídricos e a questão dos riscos. Os riscos são tema de crescente preocupação ao longo dos eventos, e referem-se a riscos relacionados tanto à quantidade quanto à qualidade da água disponível no planeta. Para o enfrentamento destes riscos se requer prevenção da poluição, mitigação de desastres naturais, gerenciamento e atenção para com as mudanças climáticas. Esta perspectiva emerge como uma das marcas temáticas mais fortes dos temas propostos para os encontros mundiais analisados.

A percepção de uma visão romântica evoluindo para uma visão voltada para a busca de soluções para a água também se salienta nos "slogans" ou grandes temas dos Fóruns: Um olhar para a água, a vida e ao ambiente ( $1^{\circ}$ Fórum), Da visão à ação ( $2^{\circ}$ Fórum), $\mathrm{O}$ Fórum como a diferença ( $3^{\circ}$ Fórum), Ações locais para a mudança global ( $4^{\circ}$ Fórum), Superando divisões de água ( $5^{\circ}$ Fórum), Tempo e soluções ( $6^{\circ}$ Fórum). A necessidade de ações, mudança, superação e soluções representam palavras de ordem a partir do segundo Fórum, assim como a esperança que estes eventos façam a "diferença". Talvez por isso passe do olhar ( $1^{\circ}$ Fórum) para a visão que leve à ação ( $2^{\circ}$ Fórum).

Quanto aos relatórios de cada Fórum, a análise dos temas que emergiram associados à palavra-chave direito humano possibilita rastrear as temáticas em voga nos documentos dos diferentes grupos participantes dos diversos continentes, para além da proposta dos organizadores exposta nos slogans e temas prioritários já analisados. 
Os temas que surgem com maior intensidade a partir do relatório do $3^{\circ}$ Fórum, (quando se tem acesso a estes documentos) foram a preocupação com o acesso à água com abastecimento em quantidade e de qualidade de modo a garantir a segurança hídrica, a saúde, a higiene, o saneamento, a subsistência e atendimento das necessidades de todos (especialmente crianças, mulheres, indígenas, marginalizados, deficientes, pobres), incluindo-se, além das necessidades físicas, as culturais e espirituais.

A água é considerada assunto estratégico porque atrela-se ao bem-estar. E também por ser percebida como um bem comum e/ou público, não sendo passível de privatização, devendo ter gestão pública e ser considerada como parte das políticas públicas prioritárias, tendo sua gestão definida a partir de processos de governança, o que requer uma gestão participativa, parceria, transparência, controle da corrupção, solidariedade entre atores, responsabilidade compartilhada, planejamento e cooperação (local, regional, nacional e internacional), e com a inclusão dos jovens no processo.

Emerge também dos relatórios a concepção da água como patrimônio natural, ao qual deve-se assegurar o controle da poluição com proteção dos ecossistemas de modo a garantir sua qualidade. Ainda, é considerada prioritária tanto para o desenvolvimento social, quanto para a produção agrícola e industrial, assim como energética, de modo a garantir a segurança alimentar.

Os relatórios analisados indicam como desafios prioritários para a questão hídrica garantir o acesso à água de qualidade e em quantidade para atender às necessidades de todos, o que é considerado um direito humano universal que deve ser incluído nas legislações nacionais (o que alguns países da América Latina já fazem) e em acordos internacionais devido a sua condição de prioridade estratégica.

Outros desafios identificados na análise textual apontam para os conflitos em torno da água, necessidade de investimentos para abastecimento e saneamento, e para tecnologias de reutilização, operacionais e outras, o crescimento populacional e as demandas decorrentes dele, o que está relacionado também às crescentes demandas dos setores produtivos, os riscos climáticos e a necessidade de exploração sustentável e conservação ambiental, o risco que as grandes corporações impõem ao pressionarem para a privatização deste bem, a gestão qualificada e participativa das águas (especialmente a partir das bacias hidrográficas), a compatibilização das diferentes necessidades que todas as formas de vida expõem, uma abordagem integral da questão hídrica que inclua as múltiplas dimensões em relação (social, política, ambiental, econômica, ética, etc..), construções de legislações que respeitem o princípio da equidade (há diferenças regionais, de perfis populacionais, entre nações, etc.. a serem respeitadas), investimentos em educação, capacitação e informação para o enfrentamento dos impactos decorrentes da falta de água ou seu acesso em situação de baixa qualidade, além da necessidade de adoção de indicadores para o monitoramento, a fim de definir critérios de abastecimento.

Constata-se que entre os Fóruns, o que teve maior participação de países foi o $5^{\circ}$ realizado na Turquia, seguido do $3^{\circ}$ Fórum, $6^{\circ}$ Fórum e $4^{\circ}$ Fórum, os quais ocorreram respectivamente em Kyoto, na França e no México. $\mathrm{O} 1^{\circ}$ Fórum, assim como o $2^{\circ}$ Fórum foram os que apresentaram menor participação de países. Este aumento de participação ao longo dos anos pode ser explicado pelo fato da relevância do assunto em nível mundial, uma vez que são crescentes os problemas relacionados à água, em especial no que diz respeito à indisponibilidade em algumas regiões do mundo, falha de gestão dos recursos hídricos e problemas decorrentes das mudanças climáticas, as quais alteram o ciclo hidrológico e, geram como consequência, conflitos em torno da água.

Além disso, observa-se também o aumento expressivo da participação da comunidade em geral, a qual teve 500 participantes em 1997, quando foi realizado o $1^{\circ}$ Fórum Mundial da Água e 34.000 participantes no $6^{\circ}$ Fórum, o que representa um aumento de $6.800 \%$. Não há 
como descartar também o crescente interesse - inclusive econômico - em torno deste bem, o que também pode ser um grande motivador do aumento da participação.

Quanto à ocorrência da palavra-chave "human rights", constatou-se que 33\% das ocorrências foram encontradas no $6^{\circ}$ Fórum Mundial da Água, seguido do $5^{\circ}$ Fórum e do $4^{\circ}$ Fórum, os quais representam respectivamente cerca de $27 \%$ e $24 \%$ do total de ocorrências. Conclui-se, desta forma, que assuntos relacionados aos direitos humanos aumentaram gradativamente, bem como a compreensão de que a água é de fato direito humano. Isto pode estar associado ao fato de que no ano anterior, em 2002, foi aprovado o Comentário Geral n ${ }^{\circ}$ 15 pela ONU, o qual reconhece o direito humano à água como um direito humano fundamental para o desenvolvimento sustentável das sociedades.

O reconhecimento e a consagração legal dos direitos humanos à água potável, embora tenham sido conquistados, ainda dependem da aplicabilidade desse direito, a fim de elaborar e avaliar políticas públicas no setor de água. Bem se sabe que as normas internacionais dos direitos humanos requerem que os serviços de água sejam fisicamente e financeiramente acessíveis, além de haver disponibilidade em quantidades suficientes, e que sejam de qualidade e aceitáveis em matéria cultural e social. No entanto, um dos maiores desafios atuais é a superação da desigualdade no acesso à água, a qual deve ser eliminada gradativamente para que os serviços sejam sustentáveis e para que os envolvidos, neste caso, a população, possa participar na tomada de decisões em relação ao respectivo assunto.

\section{AGRADECIMENTOS}

Este estudo é resultado de pesquisa apoiada pelo Conselho Nacional de Desenvolvimento Científico e Tecnológico - CNPq.

\section{REFERÊNCIAS}

BLUE GROUP DECLARATION. The Blue Group Declaration to the World Water Forum. 2012. Disponível em https://h20marsellario.files.wordpress.com/2012/03/bluegroup-on-declaration.pdf. Acesso em: 01 out. 2015.

BOLÍVIA. Constitución Politica del Estado Plurinacional de Bolivia. Derechos Fundamentales y Garantías. Artículo 20. 2008. Disponível em: http://www. harmonywithnatureun.org/content/documents/159Bolivia\%20Consitucion.pdf. Acesso em: 20 set. 2015.

EQUADOR. Constituição da República do Equador. 2009. Disponível em: http://www.stf.jus.br/repositorio/cms/portalStfInternacional/newsletterPortalInternacion alFoco/anexo/ConstituicaodoEquador.pdf. Acesso em: 04 out. 2015.

EUROPEAN COMMISSION. ACP - multi-country cooperation - water. Disponível em: http://ec.europa.eu/europeaid/regions/african-caribbean-and-pacific-acp-region/acpmulti-country-cooperation/acp-eu-water-facility_en. Acesso em: 04 out. 2015.

MORA, P. J. Acciones y Proyectos Realizados por la Red Centroamericana de Acción del Agua (FAN-CA). San José, 2004.

MORAES, R. Análise de conteúdo. Educação, v. 22, n. 37, p.7-32, 1999.

MOREIRA, R. O que é Geografia. 2. ed. São Paulo: Brasiliense, 2009. 
PEÑA, H. Estado de la política hídrica y gestión del agua: caso Chile. In: CONGRESO NACIONAL DE AGUA, 20.; SIMPOSIO DE RECURSOS HÍDRICOS DEL CONO SUR, 3., Mendoza, Argentina, 2005. Presentación... Mendoza: [s.n.], 2005.

PORTAL ODM. Acompanhamento brasileiro dos objetivos de desenvolvimento do milênio. Disponível em: http://www.portalodm.com.br/. Acesso em: 10 out. 2015.

UNITED NATIONS EDUCATIONAL, SCIENTIFIC AND CULTURAL ORGANIZATION - UNESCO. Declaração Universal dos Direitos Humanos. Paris, 1948. Disponível em: http://unesdoc.unesco.org/images/0013/001394/139423por.pdf. Acesso em: 20 abr. 2015.

UNITED NATIONS - UN. Committee on Economic, Social and Cultural Rights. General Comment 15: The right to water (Twenty-ninth session, 2003). Geneva, 2003.

UNITED NATIONS - UN. Vienna Declaration and Programme of Action (A/CONF.157/23). Vienna, 1993.

UNITED NATIONS - UN. Human Rights. Office of the High Commissioner for Human Rights, Monitoring the economic, social and cultural rights. Disponível em: http://www.ohchr.org/EN/HRBodies/CESCR/Pages/CESCRIntro.aspx. Acesso em: 05 out. 2015.

WORLD HEALTH ORGANIZATION - WHO. Drinking-Water, Sanitation and Health. 2011. Disponível em: http://apps.who.int/gb/ebwha/pdf_files/WHA64/A64_R24en.pdf?ua=1. Acesso em: 28 set. 2015.

WORLD HEALTH ORGANIZATION - WHO; STOCKHOLM INTERNATIONAL WATER INSTITUTE - SIWI. Making water a part of economic development. Stockholm: SIWI, 2002. Disponível em: http://www.who.int/water_sanitation_ health/watandmacroecon.pdf. Acesso em: 05 out. 2015.

WORLD WATER COUNCIL - WWC. Final report of the $3^{\text {th }}$ World Water Forum. Secretariat of the 3rd World Water Forum. 2003. Disponível em: http://www. worldwatercouncil.org/forum/kyoto-2003/. Acesso em: 10 jul. 2015.

WORLD WATER COUNCIL - WWC. Final report of the $4^{\text {th }}$ World Water Forum. National Water Commission of Mexico, 2006. Disponível em: http://www. worldwatercouncil.org/forum/mexico-2006/. Acesso em: 04 jul. 2015.

WORLD WATER COUNCIL - WWC. Final report of the $5^{\text {th }}$ World Water Forum. National Water Commission of Istambul, 2009. Disponível em: http://www. worldwatercouncil.org/forum/istanbul-2009/. Acesso em: 04 jul. 2015.

WORLD WATER COUNCIL - WWC. $6^{\circ}$ World Water Forum. Marseille: IFC Secretariat, 2012. Disponível em: http://www.worldwatercouncil.org/forum/marseille-2012/. Acesso em: 10 jul. 2015. 